\title{
Optimal Approach to Sporadic Desmoid Tumors: From Radical Surgery to Observation. Time for a Consensus?
}

\author{
Alessandro Gronchi, $\mathrm{MD}^{1}$ and Chandrajit P. Raut, MD, MSc $\mathrm{c}^{2,3,4}$ \\ ${ }^{1}$ Department of Surgery, Sarcoma Service, Fondazione IRCCS Istituto Nazionale dei Tumori, Milan, Italy; ${ }^{2}$ Department of \\ Surgery, Brigham and Women's Hospital, Boston, MA; ${ }^{3}$ Center for Sarcoma and Bone Oncology, Dana-Farber Cancer \\ Institute, Boston, MA; ${ }^{4}$ Harvard Medical School, Boston, MA
}

Both Mullen et al. and Peng et al. report on retrospective series of patients affected by desmoid-type fibromatosis, collected over decades, to investigate prognostic factors for outcome after surgical resection. ${ }^{1,2}$

Although not new, their conclusions add to the ongoing debate on this issue and contribute to the understanding of this disease, the approach to which is changing worldwide and should be properly codified. ${ }^{3}$

Interestingly their conclusions diverge. On multivariable analysis surgical margins are prognostic of local recurrence in the series by Mullen et al., but not in the other. ${ }^{1,2}$ On the other hand, on multivariable analysis tumor site of origin and age are prognostic of local recurrence in the series by Peng et al., but not in the other. ${ }^{1,2}$ Thus, these 2 manuscripts reflect the contradictory results found in the literature. ${ }^{4-10}$

Indeed optimal management of desmoid-type fibromatosis has not yet been defined, but surgery, if feasible, is still largely felt to be the mainstay of treatment, albeit followed by a significant local failure rate.

This being true, the first observation is that the failure rates found by both authors are somewhat higher than those from other major series (Table 1). The expected actuarial failure rate after surgery should be approximately $30 \%$ at 10 years, whereas these 2 series report 40 and $50 \%$, respectively. One possible explanation may be related to the relative short median follow-up of both (40 and 25 months, respectively). In fact, given the overall benign

(C) Society of Surgical Oncology 2012

Published Online: 8 September 2012

A. Gronchi, MD

e-mail: alessandro.gronchi@istitutotumori.mi.it

C. P. Raut, MD, MSc

e-mail: craut@partners.org nature of this disease, it is possible that patients who have not recurred within a short period postoperatively may have left the follow-up program relatively early or are continuing follow-up at centers closer to their homes rather than at these referral centers. Therefore, they may be censored relatively early despite having long disease-free intervals that is not reflected in the recurrence-free survival curve. In other words, the recurrence-free survival curves may be biased toward those developing recurrences. From a methodological standpoint, such an indolent disease should be studied in series with long follow-up times for both those who have recurred and those who have not, for a more accurate representation of recurrence rates. Surgery is an option able to control this disease in $70 \%$ of the cases. The challenge is to select the proper patients to offer a successful treatment.

The second issue that these manuscripts raise is one that has been a long-lasting question-when a decision for surgery is made, what are appropriate margins of resection $?^{4-11}$ If they are prognostically significant, then the goal of surgery should be achieving negative margins and surgical morbidity should be carefully balanced between risk of recurrence and morbidity. If not, a more relaxed approach to functional structures and function preservation may be pursued. The propensity of aggressive fibromatosis to locally recur should be related to its infiltrative nature. A positive margin clearly means that active tumor has been left behind. Why has this issue of appropriate margins remained such a persistent area of debate? One possible explanation is that the reported results may have been biased by some factors, such as the inclusion in the same series of both intra-abdominal and extra-abdominal tumors, sporadic, and FAP-associated ones, and both primary lesions and recurrences. In addition, patients may have received disparate treatments. Indeed this was also the case 
TABLE 1 Postoperative 5- and 10-year recurrence-free survival in the major single-institution series of sporadic desmoid tumors

\begin{tabular}{lllllll}
\hline & Year & No. of pts & Primary/recurrences & Median FU (months) & 5-Year RFS & 10-Year RFS \\
\hline Merchant et al. $^{4}$ & 1999 & 105 & All primary & 49 & $75 \%$ & NR \\
Gronchi et al. $^{5}$ & 2003 & 203 & $128 / 75$ & 135 & $73 \%$ & $70 \%$ \\
Lev et al. $^{6}$ & 2007 & 189 & $140 / 49$ & 63 & $80 \%$ & $79 \%$ \\
Huang et al. $^{10}$ & 2009 & 151 & $113 / 38$ & 102 & $80 \%$ & $78 \%$
\end{tabular}

pts patients, $F U$ follow-up, $R F S$ recurrence-free survival

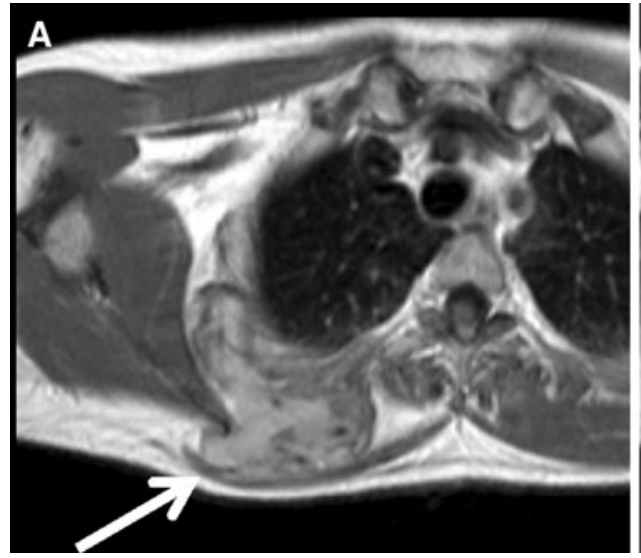

FIG. 1 Baseline contrast-enhanced T1 weighted magnetic resonance image (MRI) showing a right periscapular sporadic desmoid tumor (panel a, white arrow); 10 years later contrast enhanced T1 weighted

in the 2 series reported in this issue. In addition to all of these factors, more importantly, we believe that many if not most of these surgical series, collected over a large time span, have included both indolent and more aggressive disease. It has now been demonstrated how $50 \%$ of patients affected by primary disease and primarily observed do not progress at 5 years. ${ }^{11,12}$ Some will also eventually regress (Fig. 1). Thus, inherent tumor biology may trump other potential prognostic factors, and it is probable that such patients may undergo surgery with positive margins and will not recur. If a policy of initial observation is applied and surgery is limited to patients who progress, then quality of surgical margins is important and should be properly factored in the final decision. ${ }^{11}$

Is radiation therapy beneficial? Mullen et al. suggest that it should be considered as an option to offer when negative resection margins are not be achieved. ${ }^{1}$ This is in line with other retrospective reports. ${ }^{8,9}$. Indeed radiation therapy is active, but should be considered with caution. The benefit of radiation therapy for desmoid tumors has not been, and likely will never be, established in a randomized trial. Patients are usually young, and the risk of a second malignancy should not be underestimated. Other than patients with locally advanced mesenteric desmoids, most will not die of this disease and the potential radiation-related morbidity should always be taken into consideration. As new

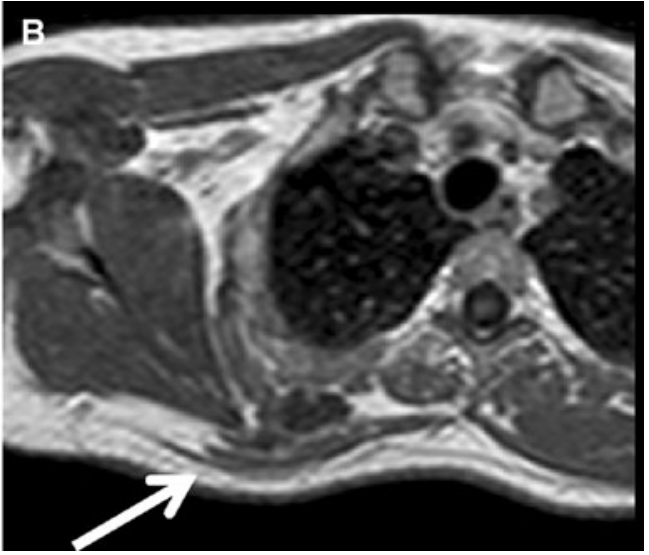

MRI showing a significant regression of the periscapular desmoid tumor (panel $\mathbf{b}$, white arrow). In the 10 years the patient underwent only watchful surveillance

radiation techniques are emerging, this may change in the future, but carefully designed studies should be carried out before recommending it on a routine basis.

Another point to factor into the decision is site of origin. Abdominal wall and sporadic intra-abdominal desmoids have a limited risk of recurrence, while extremities and girdle desmoids do have a higher risk of recurrence. The 2 reports differ on this issue, but larger series clearly favor this conclusion. ${ }^{1,2,5-7}$ Disease-related and surgery-related morbidities are also clearly different, with the abdominal wall remaining the most favorable location and the extremities/girdles the least favorable. Surgery should not render a patient more symptomatic than the disease itself, as both series conclude. The aim of the physician should be to factor all of these variables into the final decision, approaching differently favorably located tumors from unfavorably located ones.

Finally and perhaps most interestingly, both groups mention a more conservative approach as an alternative to surgery at presentation. This has been a major sea change over the last 5 to 10 years. ${ }^{3}$ We agree that until novel host and/or tumor-related biological predictors of outcome such as beta-catenine mutation type are discovered, an initial observation should become the standard approach to all patients affected by sporadic desmoid-type fibromatosis, to avoid overtreatment of half of them. ${ }^{3,12,13}$ For the patients 
who progress, surgery may be reasonable when negative margin resection can be achieved at a reasonable price (i.e., abdominal wall and most intra-abdominal locations). When this is not the case (typically in the extremity/girdle locations), an alternative treatment should be offered and surgery and/or radiation therapy used as a salvage therapy, when all other possibilities, including persistent observation of slow-growing and indolent disease, fail.

A global consensus on the optimal approach to this disease should be welcome.

\section{REFERENCES}

1. Mullen JT, DeLaney TF, Kobayashi WK, et al. Desmoid Tumor: analysis of prognostic factors and outcomes in a surgical series. Ann Surg Oncol. doi:10.1245/s10434-012-2638-2.

2. Peng PD, Hyder O, Turley R, Groeschl R, Firoozmand A, Lidsky $\mathrm{M}$, et al. Management and recurrent patterns of desmoid tumors: a multiinstitutional analysis of 211 patients. Ann Surg Oncol. doi: 10.1245/s10434-012-2634-6.

3. Casali PG, Blay JY. Soft tissue sarcomas: ESMO Clinical Practice Guidelines for diagnosis, treatment and follow-up. Ann Oncol. 2010;21:v198-v203.

4. Merchant NB, Lewis JJ, Woodruff JM, Leung DH, Brennan MF. Extremity and trunk desmoid tumors: A multifactorial analysis of outcome. Cancer. 1999;86:2045-52.

5. Gronchi A, Casali PG, Mariani L, Lo Vullo S, Colecchia M, Lozza L, et al. Quality of surgery and outcome in extra- abdominal aggressive fibromatosis: A series of patients surgically treated at a single institution. J Clin Oncol. 2003;21:1390-7.

6. Lev DC, Kotilingam D, Wei C, Ballo MT, Zagars GK, Pisters PW, et al. Optimizing treatment of desmoid tumors. J Clin Oncol. 2007;25:1785-91.

7. Salas S, Dufresne A, Bui B, Blay JY, Terrier P, Ranchere-Vince $\mathrm{D}$, et al. Prognostic factors influencing progression-free survival determined from a series of sporadic desmoid tumors: a wait-andsee policy according to tumor presentation. J Clin Oncol. 2011;29:3553-8.

8. Spear MA, Jennings LC, Mankin HJ, Spiro IJ, Springfield DS, Gebhardt MC, et al. Individualizing management of aggressive fibromatoses. Int J Radiat Oncol Biol Phys. 1998;40:637-45.

9. Ballo MT, Zagars GK, Pollack A, Pisters PW, Pollack RA. Desmoid tumor: prognostic factors and outcome after surgery, radiation therapy, or combined surgery and radiation therapy. $J$ Clin Oncol. 1999;17:158-67.

10. Huang K, Fu H, Shi YQ, Zhou Y, Du CY. Prognostic factors for extra-abdominal and abdominal wall desmoids: a 20-year experience at a single institution. J Surg Oncol. 2009;100:563-9.

11. Bonvalot S, Eldweny H, Haddad V, Rimareix F, Missenard G, Oberlin $\mathrm{O}$, et al. Extra-abdominal primary fibromatosis: Aggressive management could be avoided in a subgroup of patients. Eur J Surg Oncol. 2008;34:462-8.

12. Fiore M, Rimareix F, Mariani L, Domont J, Collini P, Le Péchoux C, et al. Desmoid-type fibromatosis: a frontline conservative approach to select patients for surgical treatment. Ann Surg Oncol. 2009;16:2587-93.

13. Lazar AJ, Tuvin D, Hajibashi S, Habeeb S, Bolshakov S, Mayordomo-Aranda E, et al. Specific mutations in the beta-catenin gene (CTNNB1) correlate with local recurrence in sporadic desmoid tumors. Am J Pathol. 2008;173:1518-27. 